\title{
New low-dose, extended-cycle pills with levonorgestrel and ethinyl estradiol: an evolutionary step in birth control
}

This article was published in the following Dove Press journal:

International Journal of Women's Health

2 May 2010

Number of times this article has been viewed

\author{
Anita Nelson \\ Harbor-UCLA Hospital, Los Angeles \\ Biomedical Research Institute, Los \\ Angeles, CA, USA
}

Correspondence:Anita Nelson Los Angeles Biomedical Research Institute, I 457 3rd Street, Manhattan Beach, CA 90266, USA

Email anitalnelson@earthlink.net
Aim: To review milestones in development of oral contraceptive pills since their introduction in the US 50 years ago in order to better understand how a new formulation with low-dose estrogen in an extended-cycle pattern fits into the evolution of birth control pills.

Methods: This is a review of trends in the development of various birth controls pills and includes data from phase III clinical trials for this new formulation.

Results: The first birth control pill was a very high-dose monophasic formulation with the prodrug estrogen mestranol and a first-generation progestin. Over the decades, the doses of hormones have been markedly reduced, and a new estrogen and several different progestins were developed and used in different dosing patterns. The final element to undergo change was the 7-day pill-free interval. Many of these same changes have been made in the development of extended-cycle pill formulation.

Conclusion: The newest extended-cycle oral contraceptive formulation with 84 active pills, each containing $20 \mu \mathrm{g}$ ethinyl estradiol and $100 \mu \mathrm{g}$ levonorgestrel, represents an important evolution in birth control that incorporates lower doses of estrogen (to reduce side effects and possibly reduce risk of thrombosis), fewer scheduled bleeding episodes (to meet women's desires for fewer and shorter menses) and the use of low-dose estrogen in place of placebo pills (to reduce the number of days of unscheduled spotting and bleeding). Hopefully, this unique formation will motivate women to be more successful contraceptors.

Keywords: extended-cycle oral contraceptives, low-dose extended-cycle pills, Lo Seasonique

\section{Introduction}

The recent introduction of a low-dose, extended-cycle oral contraceptive pill with levonorgestrel (LNG) and ethinyl estradiol (EE) represents an important evolutionary step in contraception, reflecting the importance of reducing the hormone levels of the active pills while eliminating hormone-free intervals entirely.

To appreciate each of these advances, it is necessary to review briefly the history of oral contraceptives (OCs). Such a review is especially relevant as we are celebrating the 50th year of the introduction of birth control pill in the United States. Despite 50 years of pill and the availability of many effective contraceptives, nearly half of US pregnancies are still unintended. In typical use, the first-year failure rate of OCs is $8.4 \% .{ }^{1}$ It has been estimated that one million pill users get pregnant each year, usually as a result of inconsistent pill use. ${ }^{2,3}$ In order to help women achieve the full contraceptive potential offered by pills with correct and consistent use, several innovative strategies have been employed over the years. Lower doses of estrogen have been used to reduce side effects such as breast tenderness and nausea, but those lower-dose formulations 
increased the risk of unscheduled spotting and bleeding, and early discontinuation. ${ }^{4}$ At the same time, lower-dose pills may not suppress ovarian activity as well as higher-dose OCs. ${ }^{5}$ The pill-free interval has been shortened in some formulations and eliminated in others to reduce ovarian folliculogenesis during the pill-free interval. ${ }^{6-9}$ and, thereby, decrease spotting and bleeding and the risk of escape ovulation. ${ }^{10,11}$ Noncontraceptive benefits have been popularized to incentivize women to use pills more consistently. ${ }^{12}$

The first formulation approved for contraception (Envoid-10 ${ }^{\circledR}$ ) was a monophasic pill with 21 active pills and 7 placebo pills. Each active pill contained $150 \mu \mathrm{g}$ mestranol and $9.85 \mathrm{mg}$ norethynodrel. By today's standards, this is an enormous amount of progestin; if a woman were to swallow all at once every one of the 21 active pills in a pack of a modern pills (eg, Ovcon 35 ${ }^{\circledR}$; Warner Chilcott, Rockaway, NJ, USA), she would get less progestin than women consumed every day with one tablet of Enovid.

While these high doses of sex steroids caused considerable side effects, women took these early birth control pills with enthusiasm because the pills provided women for the first time in history an opportunity to reliably control their fertility and the timing of their bleeding. The importance of this second feature has not received adequate recognition. Rather than having to rearrange their lives at the time of their menses, women on the pill could plan their lives around predictable (and usually lighter and less painful) scheduled bleeding episodes. Both of these features contributed significantly to the ability of women to compete more successfully in the job market.

The use of placebo pills to induce monthly scheduled bleeding (which the user would recognize as the menses) was essential to the original acceptance of the pill. Some have suggested that the placebo pills were included for political reasons - to obtain papal approval of the pill ${ }^{13}$ - but at the time of the pill introduction there were important patientbased reasons for the placebo pills. Many of the side effects that women endured with the early, high-dose pills mimicked pregnancy. Nausea and vomiting were frequent problems. Breast tenderness and abdominal bloating were also common. Melasma was rampant. ${ }^{14}$ In the face of all these symptoms, it was important that women using the pill be reassured that they were not pregnant. The only pregnancy test available in 1960 was not suitable because it required 6 weeks of amenorrhea before it could detect pregnancy and took 2 to 3 days to perform. However, periodic bleeding induced by placebo pills provided users with timely reassurance that they were not pregnant and could confidently start use of another cycle of pills. The bleeding also calmed women's concerns about possible adverse impacts the pill might have on their reproductive system and long-term fertility.

The choice of the number of placebo pills (7) was more scientifically based. Even though the so-called "first generation" progestins (norethindrone) had relatively short half-lives ( 4 to 8 hours), circulating levels of progestin were so high that it often took 4 to 5 days for those levels to drop sufficiently to permit endometrial sloughing. To allow for variations in metabolic clearance rates so that virtually women would start bleeding, 7 days of placebo were used.

\section{New hormones and lower doses for birth control pills}

Early in the 1960s, the medical hazards posed by high-dose estrogen (hypertension and venous and arterial thromboembolism) became apparent. Although these serious events were relatively rare, they developed more frequently in vulnerable women. In response to these problems, restrictions were placed on women who were candidates for oral contraceptive use and the doses of estrogen were reduced. Women with histories of deep venous thrombosis, myocardial infarction, stroke or hypertension were no longer offered pills. The dose of mestranol was reduced first to $100 \mu \mathrm{g}$, then to $80 \mu \mathrm{g}$, and later to $50 \mu \mathrm{g}$. The doses of progestin were decreased to balance the estrogen doses.

With each reduction in the estrogen (mestranol), a measurable decrease was observed in venous thrombosis (and pulmonary embolism). ${ }^{15}$ Mestranol is a prodrug and requires hepatic cleavage to convert it into its active form - ethinyl estradiol. The conversion rate varies between individuals, but $50 \mu \mathrm{g}$ mestranol is generally equivalent to 35 to $40 \mu \mathrm{g} \mathrm{EE}$. EE replaced mestranol in most of the $50 \mu \mathrm{g}$ formulations and in all the sub-50 pills.

However, as the sex steroids in the active pills were reduced, women started to complain more frequently about unscheduled spotting and bleeding. In order to minimize that problem, longer-acting progestins were developed. Norgestrel and LNG (the biologically active dl-norgestrel form) significantly decreased the problem of what was called at that time "breakthrough bleeding". Paired with $30 \mu \mathrm{g} \mathrm{EE}$, these new formulations were very popular because they also reduced many of the estrogen-related side effects, most notably melasma. While LNG provided significant cycle control in both its monophasic and multiphasic formulations, some users were sensitive to its relatively high androgenicity and complained about acne and hirsutism. Clinicians also voiced concerns about possible adverse metabolic impacts 
of the relatively androgenic compounds on lipids, especially HDL-C and LDL-C. ${ }^{16}$

In response to those concerns, long-acting progestins with less androgenic impact (gestodene, norgestimate and desogestrel) were developed. More recently, an antiandrogenic progestin derived from $17 \beta$-spirolactone has been marketed. These newer progestins have added new on-label noncontraceptive benefits that have been appreciated by users. The first approved formulation for treatment of mild to moderate acne was a multiphasic norgestimate pill (Ortho TriCyclen $^{\circledR}$; Ortho-McNeil-Janssen Pharmaceuticals, Raritan, NJ, USA). A low-dose drospirenone-containing formulation (Yaz ${ }^{\circledR}$; Bayer HealthCare, Tarrytown, NY, USA) is Food and Drug Administration (FDA) approved for two noncontraceptive applications: the treatment of mild to moderate acne and the treatment of premenstrual dysphoric disorder (PMDD) in women using OCs for birth control. These new applications increased both provider and user enthusiasm for their use.

The newer, less androgenic progestins allowed fuller expression of the estrogen on hepatic production of SHBG (pivotal to success in treatment of acne). As a result, there were concerns that hepatic production of thrombotic and antithrombotic factors would also be altered by these less androgenic formulations and result in increased risk for thromboembolism. Large epidemiologic studies in the 1990s suggested that the LNG compounds may be associated with lower incidence of venous thromboembolic (VTE) events (deep venous thrombosis and pulmonary embolism) than the less androgenic progestin formulations. ${ }^{17-20}$ Unfortunately, issues of selection bias and recency of use may have compromised the strength of those early findings. However, many manufacturers of third-generation progestins in the US amended their product labeling to allow for the possibility higher risks of VTE with pills with these progestins.

More recently, several very large epidemiologic studies with a variety of designs have re-examined this issue. Two large-scale studies required by the FDA for post-marketing surveillance of drospirenone-containing pills. One study provided prospective information on women in Europe (the EURAS study). ${ }^{21}$ In the US a claims-based study compared VTE risk using an array of different progestins and different doses of estrogen. Those studies found that, when adjusted for estrogen dose and known risk factors for thrombosis (such as age, obesity), there were no significant differences among the rates of VTE, although one study found that the LNG formulations did have lower risk of VTE. ${ }^{22}$ All formulations had much lower VTE risk than pregnancy. Two recent claims based and registry based studies from Europe have added additional, but less accurate information. The authors of those studies concluded that LNG pills posed slightly less DVT risk than drospirenone or third-generation progestins, but more importantly, they also demonstrated that pills with $20 \mu \mathrm{g}$ EE had lower risk of thrombosis than did 30 to $40 \mu \mathrm{g}$ formulations. ${ }^{23,24}$

\section{Changes in the placebo pills}

As early as the 1970s, clinicians found that birth control pills could help arrest the growth of endometriotic implants by inducing a "pseudo pregnancy" state. When clinicians eliminated the placebo pills for months at a time, pills also provided relief from the severe dysmenorrhea which women with endometriosis suffered. ${ }^{25,26}$ The most common pills used for this indication contained norgestrel/LNG, because the long-half of this progestin limited unscheduled bleeding and spotting and its potency induced marked therapeutic changes in the endometriotic implants. Later, uninterrupted pill use was recommended to help women who suffered from menstrual migraines. ${ }^{27,28}$ Episodically, women extended their pill cycles to prevent bleeding at inopportune times (honeymoons, travel dates, religious holidays). The first product to formally change the standard 7 placebo pills, was a low-dose desogestrelcontaining formulation, (Mircette ${ }^{\circledR}$; Duramed Pharmaceuticals, Pomona, NY, USA) which replaced the last 5 placebo pills with 5 tablets each with $10 \mu \mathrm{g}$ EE. This substitution was made to try to reduce "estrogen withdrawal" symptoms during the scheduled bleeding episodes and as well as to decrease unscheduled spotting/bleeding in the subsequent cycle.

A more sustained change in the placebo pills was prompted by landmark research conducted by Sulak et al. ${ }^{29}$ These investigators persuaded women who wanted to discontinue their OCs because of unpleasant side effects to continue using the pills and to chronicle the timing those problems in the cycle. If the problems had been randomly distributed, the prevalence of problems would have been 3 times greater during the 3 weeks of active pill use compared to the 1 week of placebo use. If the side effects were due to the hormones of the birth control pills, the frequency of problems during active pill taking days would be even higher. However, distribution of complaints over the cycle was found to be exactly opposite. Women suffered problems such as headache, pelvic pain and cramping, breast tenderness, bloating and swelling and used pain relievers most often during the placebo-pill days (see Table 1). In a follow-up study, Sulak et al found that $74 \%$ women with pill-free interval problems (such as migraine, dysmenorrhea, heavy bleeding, and acne) were stabilized on extended-cycle regimens. ${ }^{30}$ 
Table I Distribution of "pill-related" problems during the pill cycle

\begin{tabular}{lll}
\hline & \multicolumn{2}{l}{ Percent of women complaining } \\
\cline { 2 - 3 } & $\begin{array}{l}\text { 2I days of active } \\
\text { pills }\end{array}$ & $\begin{array}{l}\text { 7 days of placebo } \\
\text { pills }\end{array}$ \\
\hline Complaints* & \\
Pelvic pain & $21 \%$ & $70 \%$ \\
Headache & $53 \%$ & $70 \%$ \\
Breast tenderness & $19 \%$ & $58 \%$ \\
Bloating/swelling & $16 \%$ & $38 \%$ \\
Use of pain medication & $43 \%$ & $69 \%$ \\
\hline From data of Sulak et al. ${ }^{29}$ & & \\
$* P$ values for all complaints $<0.001$ versus placebo. &
\end{tabular}

Willis et al demonstrated the importance of shortening (or eliminating) the pill free interval to control ovarian activity with low-dose pill formulations. Gonadotropins (LH and FSH) and ovarian follicular activity (measured by estradiol and inhibin B levels) were found to increase greatly after only 3 to 4 days of placebo use. However, this rise was blunted if active pills were started early. ${ }^{31}$ In another study, women who had a 7-day pill-free interval experienced less follicular suppression than did women who were supplemented by estrogen alone or estrogen plus progestin. ${ }^{32}$ Ovarian activity in overweight women was even less suppressed than seen in normal-weight women. Kippling et al demonstrated the impact of shortening the pill-free interval by measuring follicle size, estrogen and progesterone levels. With the 7-day pill-free interval, no ovulation was observed, but the mean dominant follicle size in the next cycle reached $10 \mathrm{~mm}$. With a 3-day delay in a start of the next pill pack, that dimension reached almost $15 \mathrm{~mm}$, quite capable of ovulation. ${ }^{33}$ It should be noted that with shorter-acting progestins, shortening the pill-free interval from 7 to 4 days did not change ovarian activity measured by follicle size, Hoogland scores, and ovarian steroid hormone production, or change bleeding patterns. $^{34}$

In addition to reducing pill-related complaints, extendedcycle pills provide significant health benefits. Reducing the numbers of scheduled bleeding episodes results in less blood loss. This can be very important to women with sickle cell anemia, fibroids, bleeding distresses or conditions that require use of medications that interfere with vitamin K synthesis. The pain and suffering that women experience with their monthly bleeding is generally reduced with conventional pill use, but extended-cycle use enhances that benefit. With menses women suffer back pain, abdominal pain, bloating, constipation, headache, breast tenderness, irritability, depressed mood, fatigue, nausea and even vomiting. These complaints are decreased with an extended-cycle oral contraceptive regimen.${ }^{35}$ Complaints about headache, mood changes and pelvic pain were clearly diminished with extended-cycle use of a drospirenone-containing pill compared to its cyclic use. ${ }^{36}$ Estimates are that nearly one-third of the 2.5 million US women with menstrual disorders report spending an average of 9.6 days in bed each year because of these problems. ${ }^{37}$ Monthly episodes of these complaints result in lower productivity, more lost days of work and less opportunity for career advancement. Dysmenorrhea has been reported to be the number one cause of lost days of school and work in women up to age $25 .{ }^{38}$ In a Harris poll, $35 \%$ of women in every age group agreed with the statement that they had periodic cramps, and other symptoms that caused interference with social events, friends and family, physical/athletic opportunity and professional commitments. ${ }^{39}$

\section{Oral contraceptive formulation with extended cycle: first FDA-approved product}

The first FDA-approved oral contraceptive pill to reduce the numbers of scheduled bleeding episodes was a monophasic formulation with 84 days of pills with $30 \mu \mathrm{g}$ ethinyl estradiol and $150 \mu \mathrm{g} \mathrm{LNG}$, followed by 7 days of placebo pills called Seasonale ${ }^{\circledR}$ (Duramed Pharmaceuticals, Pomona, NY, USA). Although there was relatively slow uptake of this product, women who used it found that it helped them overcome another real world barrier that pill users often face - the need to return to pharmacies for monthly refills. By packing 3 cycles in 1 packet, women had to invest less time physically obtaining their pills. The advantage of this can be seen in a study of timely contraceptive prescription refills which followed 1.7 million women who initiated use of wide variety of hormonal contraceptive methods. Of all the products studied, there were only two that $30 \%$ of women refilled on a timely basis for 1 year. Seasonale ${ }^{\circledR}$ was one of these products. ${ }^{12}$

Total numbers of days of spotting and bleeding are fewer with the $84 / 7$ formulation (48.2/year) compared to the conventional 28-day packets of the same formulation (50.8/year). ${ }^{40}$ Most remarkably, the number of days of scheduled bleeding and spotting was not only less with the $84 / 7$ formulation (10.6/90 days) than with the conventional 21/7 formulation (34.4/90 days), but the number of days of scheduled bleeding after 84 active pills was less than the number of days of bleeding during any one scheduled bleeding episode using 28 day cycles. The endometrial stripe measured of extended-cycle pill on day 84 was also thinner than the endometrial stripe at day 21 with conventional cycling. This is an 
important finding, because women who have experienced a cycle or two of anovulation know that when their bleeding ultimately starts, the flow is heavier and longer than usual. Many women worry that extended-cycle OC use will consolidate their bleeding into heavier periods. Reassuring them that scheduled bleeding is lighter and shorter may remove another unspoken fear.

Table 2 shows that total number of days with spotting and/or bleeding was less with use of extended-cycle OCs, but the median number of days of unscheduled bleeding and spotting days (37.6) was greater than that seen in monthly cycling OC users (14.8). However, the median number of days of unscheduled spotting and bleeding dropped from 12 days in the first 3 months to 6 days in the next 2 cycles. By the last packet, the unscheduled spotting and bleeding days with extended cycle (about 1 day per 28-day cycle) was the same as seen with 28 -day-cycle pills. ${ }^{40}$ Unscheduled bleeding and spotting is a feature clinicians fear because of past experience with complaints of "breakthrough bleeding" with low-dose pills. Counseling before initiation of the extended-cycle pill use can diminish those concerns. Women who enrolled in the clinical trials were counselled about the probability of temporary increase in the numbers of unscheduled days of spotting and bleeding; only $7.7 \%$ of subjects discontinued pill use for "unacceptable bleeding". ${ }^{40}$ Efficacy in that trial was better for the extended-cycle pill form ( $0.9 \%$ Pearl Index $)$ vs conventional 28 -day cycle (1.3\% Pearl Index). No woman with a body weight in excess of $90 \mathrm{~kg}$ became pregnant. In a systematic Cochrane review of randomized controlled trials of extended-cycle oral contraceptive compared to 28-day cycles, Edelman et al found that compliance and satisfaction were similar. Bleeding patterns were equivalent or improved by continuous-dosing regimens but the continuous-dosing

Table 2 Bleeding patterns with $30 \mu \mathrm{gE} / \mathrm{I} 50$ LNG pills given in extended cycles vs conventional cycle

\begin{tabular}{|c|c|c|c|c|}
\hline \multirow[b]{3}{*}{ Total days of } & \multicolumn{4}{|c|}{ Number of days in I year } \\
\hline & \multicolumn{2}{|c|}{ Extended cycle } & \multicolumn{2}{|c|}{ 28-day cycle } \\
\hline & Mean & Median & Mean & Median \\
\hline Bleeding and/or spotting & 48.2 & 35 & 50.8 & 53 \\
\hline Bleeding only & 22.7 & 16.0 & 37.0 & 39.5 \\
\hline \multicolumn{5}{|l|}{ Scheduled days } \\
\hline Bleeding and/or spotting & 10.6 & 10.0 & 32.4 & 36.0 \\
\hline Bleeding only & 7.9 & 2.0 & 27.0 & 29.0 \\
\hline \multicolumn{5}{|l|}{ Unscheduled days } \\
\hline Bleeding and/or spotting & 37.6 & 26.0 & 14.8 & 7.0 \\
\hline Bleeding only & 18.3 & 13.0 & 9.9 & 5.5 \\
\hline
\end{tabular}

From data of Anderson et al..$^{40}$ group had more improvement in menstrual-related problems such as headaches, fatigue, bloating and menstrual pain. ${ }^{41}$

\section{Oral contractive formulations with extended cycles: changes in the placebo pills}

In an attempt to reduce the numbers of days of unscheduled bleeding and spotting without increasing the number of scheduled bleeding episodes, the next product introduced replaced the 7 placebo pills with 7 pills each containing $10 \mu \mathrm{g}$ EE (Seasonique ${ }^{\circledR}$; Duramed Pharmaceuticals Pomona NY, USA). In a study of pituitary - ovarian activity in 3 different formulations: 21/7, 84/7 (7 placebo pills) and 84/7 (7 pills with EE), investigators found that those receiving the $10 \mu \mathrm{g}$ EE pills had significantly lower levels of both FSH and $\mathrm{E}_{2}$ $(P<0.05)$. In addition, fewer developing follicles were seen during the active pills of the next cycle. ${ }^{6}$ As expected, both the $84 / 7$ placebo and $84 / 7 \mathrm{EE}$ formulation users reported less menstrual flow than did women on 21/7-day regimen. ${ }^{6}$ In a cross-study analysis comparing the outcomes of the phase 3 trials for each $84 / 7$-day product, it was seen that scheduled bleeding with the 84/7-EE regimen was less during in each of the scheduled bleeds compared to the 84/7-placebo regimen. Also, unscheduled bleeding decreased more quickly with the 84/7-EE regimen, with significant differences seen during the third cycle. ${ }^{42}$ On an intent-to-treat basis, the Pearl Index was 1.27 for the newer formulation. This included 2 pregnancies in women which occurred within 14 days of discontinuing the pills. ${ }^{43}$ The FDA now requires that these pregnancies be counted as contraceptive failures, rather than using them to demonstrate rapid return to fertility.

\section{Oral contraceptive formulations with extended-cycle: lower-dose formulations}

Kwiecien et al compared the effects of low-dose $(20 \mu \mathrm{g}$ EE) LNG $(100 \mu \mathrm{g})$ pills given cyclically $(21 / 7)$ to extended-use $163 / 7$. Total bleeding days were fewer in the extended-cycle group (25.9 vs 34.9 days) and there were fewer bleeding days requiring protection in the extended-cycle group (18.4 vs 33.8 days $P<0.01$ ). They also reported significantly fewer days of bloating and menstrual pain with extended-cycle use. ${ }^{44}$ When the same pill was used in a randomized, controlled study comparing 12 cycles of uninterrupted use to a conventional $21 / 7$ regimen, fewer total days of bleeding occurred in the continuous-use $\operatorname{arm} .{ }^{45}$ In a different study, which directly compared days of amenorrhea with 
extended-cycle use, the LNG arm with $20 \mu \mathrm{g}$ EE pills resulted in a higher median number of days of amenorrhea during the first 90 days (71 days) than was seen in the $30 \mu \mathrm{g}$ EE/LNG $\operatorname{arm}(67$ days). There were also fewer days of spotting in the lower-dose arm. ${ }^{46}$

The FDA approved a low-dose continuous regimen of $20 \mu \mathrm{g} \mathrm{EE} / 90 \mu \mathrm{g}$ LNG pills that were used for up to 13 cycles of use (Lybrel ${ }^{\circledR}$; Wyeth Pharmaceutical, Philadelphia, PA, USA). The Pearl Index pregnancy rate was 1.60 on-treatment. The onset of amenorrhea (no bleeding or spotting) was somewhat slow with this formulation, but by cycle $13,58.7 \%$ of subjects had complete amenorrhea and another $23.0 \%$ had only spotting but no bleeding. Only 921 of the 2134 women who took at least 1 dose of drug completed the 12-month study; $56 \%$ of study participants discontinued early. ${ }^{47}$

More recently, a randomized open-label European study of daily use of pills with $20 \mu \mathrm{g} \mathrm{EE} / 90 \mu \mathrm{g}$ LNG vs cyclic use of pills with (21/7) $20 \mu \mathrm{g} \mathrm{EE} / 100 \mu \mathrm{g}$ LNG, reported that there were no pregnancies in the continuous $\mathrm{OC}$ arm, but the Pearl Index in the cyclic OC arm was 1.19. Amenorrhea was achieved by $40 \%$ of women in the extended-cycle arm by pill pack 7 and by $53 \%$ by the last cycle. Another $26 \%$ had only spotting by that last cycle. ${ }^{48}$ The discontinuation rate for the continuous formulation was $33.1 \%$ compared to $21.7 \%$ in the cyclic arm. Many other features of this formulation have been reported. Continuous pill use completely suppressed ovulation, with little evidence of follicular development during a 90-day study. Return of ovulation after cessation was rapid. ${ }^{49}$ In a study of explicit return to fertility, the pregnancy rate was $52 \%$ by 3 months after cessation, and $86 \%$ at 13 months. ${ }^{50}$ Median return to menses was 32 days; $98.9 \%$ of women had return of menses or pregnancy by 90 days. ${ }^{51}$ To prevent possible confusion between anovulatory causes of amenorrhea (which could place a woman at risk for endometrial hyperplasia) and menstrual suppression with continuous combination OCs, endometrial safety with this continuous formulation was demonstrated by endometrial aspiration at the end of 13 cycles; no hyperplasia or malignancy was detected. ${ }^{52}$ Finally, adverse menstrual-cycle related symptoms were significantly improved within 3 months of initiation or continuous OCs. ${ }^{53}$ The Endicott Work Productivity Scale also showed improved with continuous OC use compared to baseline ${ }^{54}$ Only $18.6 \%$ of women in this study discontinued pill use.

The latest FDA-approved in extended-cycle contraceptive pill is an $84 / 7$ formulation with 84 tablets of $20 \mu \mathrm{g} \mathrm{EE} / 100 \mu \mathrm{g}$ LNG and 7 tablets with $10 \mu \mathrm{g}$ EE each - Lo Seasonique ${ }^{\circledR}$ (Duramed Pharmaceuticals, Pomona, New York, USA). This formulation builds on the popularity of low-dose estrogen. This formulation has a slightly higher dose of progestin $(100 \mu \mathrm{g} v s 90 \mu \mathrm{g})$ than the prior FDA-approved 13-cycle product $\left(\right.$ Lybrel $\left.^{\circledR}\right)$. The $100 \mu \mathrm{g}$ dose is equivalent to the dose used in the open label European study of continuous OCs. Four scheduled bleeding episodes are induced each year to meet the desires of many women to reduce, but not eliminate their "menstruation" 55,39 and to more rapidly reduce the numbers of days of unscheduled bleeding and spotting.

In the phase 3 clinical trial, 2,185 women provided 20,937 28-day cycles of exposure. ${ }^{56}$ Women aged 18 to 40 were studied for safety outcomes. Pregnancy rates were calculated for the group as a whole and for women age 18 to 35 . The Pearl Index for pregnancies in the 18 to 35 age group in their intent to treat population adjusted for use of other methods was 2.74, including pregnancies that occurred within 14 days of drug cessation. Three of the pregnancies were never verified and 4 occurred in the second week following pill cessation. Interestingly, the weight of the subjects in this study was very representative of typical American women; they ranged from 87 to 381 pounds ( 40 to $175 \mathrm{~kg}$ ), with a mean weight of 158.7 pounds $(72.8 \mathrm{~kg})$. Over a quarter of women were obese and $12.4 \%$ had BMI $>40$. Earlier retrospective studies had voiced the concern that lower-dose OCs may be associated with higher pregnancy rates among women weighing more than $70 \mathrm{~kg} .{ }^{57,58}$ In this clinical study, there was no trend to increased pregnancy rates in heavier women. Distributing the women into deciles based on weight at entry into the study, the lowest pregnancy rate $(0.47 \%)$ was seen in the sixth decile and the highest $(2.75 \%)$ was found in the fifth decile.

Scheduled bleeding and/or spotting usually lasted 2 to 3 days every 91-day cycle. Unscheduled spotting and bleeding diminished progressively with longer use. The median number of days with unscheduled bleeding in the first 91-day period was 15 and unscheduled spotting added a median of 10 days during the first 91 -day cycle ( 2.5 days/28 day cycle). By the fourth cycle, the median number of unscheduled bleeding days was 0 , and the median number days of unscheduled spotting was 3 per 91-day cycle. Looking at the data another way, it can be seen that $44 \%$ of women had at least 20 days (more than 6 days per 28-day cycle) of unscheduled bleeding and spotting the first cycle, but by the fourth cycle only $19 \%$ of women had that extensive a problem. Interestingly, of those $19 \%$, only $3 \%$ had prolonged bleeding; the other $16 \%$ experienced only prolonged spotting. Complete amenorrhea was reported by $6.2 \%$ of subjects first cycle and by $17.4 \%$ in the last cycle. In this study, $57.2 \%$ of women completed the entire trial; $9.6 \%$ discontinued early, 
at least in part due to bleeding and/or spotting. ${ }^{57}$ These numbers compare quite favorably to the pattern seen with higher-dose (30 $\mu \mathrm{g}$ EE) 84/7 (placebo) formulation. The safety profile was reported to be similar to that found with other OCs. Importantly, even in this heavier, older study population, there were no reports of venous thromboembolic events.

\section{Conclusion}

As we celebrate the 50th anniversary of the first birth control pill, it is interesting to reflect on the many changes that birth control pills have undergone in response to patient preferences and safety considerations. One of the last features of the birth control pill to change was the number and content of placebo pills. Once it was recognized that scheduled bleeding with birth control pills has no medical benefit and can cause suffering and discontent with pills, products with extended cycles were introduced. Those products have over time repeated much of the history of the earlier monthly cyclic formulations. This latest extended formula represents many of the evolutionary changes that have been made to "the pill" to increase pill safety (decreased estrogen doses) and to encourage correct and consistent pill use by minimizing side effects (unscheduled bleeding and spotting) and by providing important noncontraceptive benefits (decreased numbers of scheduled bleeding episodes). It has been tested in women who more accurately reflect the US population in weight. By advancing in all of these important directions, this new formation represents an important new option to help women more successfully contracept.

\section{Disclosures}

Research (Grants): Bayer HealthCare, Pfizer (Wyeth), Teva; Speaker's Bureau (Honoraria): Bayer, Merck (ScheringPlough), KV Pharmaceuticals, Pfizer (Wyeth), Teva; Advisory Boards (Honoraria): Bayer, Merck (Schering-Plough), Ortho-McNeil, Proctor and Gamble, Teva, Xanodyne.

\section{References}

1. Kost K, Singh S, Vaughan B, Trussell J, Bankole A. Estimates of contraceptive failure from the 2002 National Survey of Family Growth. Contraception. 2008;77(1):10-21.

2. Rosenberg MJ, Waugh MS, Long S. Unintended pregnancies and use, misuse and discontinuation of oral contraceptives. J Reprod Med 1995;40(5):355-360.

3. Potter L, Oakley D, de Leon-Wong E, Cañamar R. Measuring compliance among oral contraceptive users. Fam Plann Perspect. 1996;28(4):154-158.

4. Gallo MF, Nanda K, Grimes DA, Schulz KF. Twenty micrograms vs $>20$ microg estrogen oral contraceptives for contraception: systematic review of randomized controlled trials. Contraception. 2005;71(3): $162-169$.
5. Fauser BC, Van Heusden AM. Manipulation of human ovarian function: physiological concepts and clinical consequences. Endocr Rev. 1997;18(1):71-106.

6. Vandever MA, Kuehl TJ, Sulak PJ, et al. Evaluation of pituitary-ovarian axis suppression with three oral contraceptive regimens. Contraception. 2008;77(3):162-170.

7. Klipping C, Duijkers I, Trummer D, Marr J. Suppression of ovarian activity with a drospirenone-containing oral contraceptive in a $24 / 4$ regimen. Contraception. 2008;78(1):16-25. Erratum in: Contraception. 2008;78(4):350.

8. Schlaff WD, Lynch AM, Hughes HD, Cedars MI, Smith DL. Manipulation of the pill-free interval in oral contraceptive pill users: the effect on follicular suppression. Am J Obstet Gynecol. 2004;190(4):943-951.

9. Reape KZ, DiLiberti CE, Hendy CH, Volpe EJ. Effects on serum hormone levels of low-dose estrogen in place of placebo during the hormone-free interval of an oral contraceptive. Contraception. 2008;77(1):34-39.

10. Spona J, Feichtinger W, Kindermann C, Wünsch C, Brill K. Inhibition of ovulation by an oral contraceptive containing 100 micrograms levonorgestrel in combination with 20 micrograms ethinylestradiol. Contraception. 1996;54(5):299-304.

11. Endrikat J, Gerlinger C, Plettig K, et al. A meta-analysis on the correlation between ovarian activity and the incidence of intermenstrual bleeding during low-dose oral contraceptive use. Gynecol Endocrinol. 2003;17(2):107-114.

12. Nelson AL, Westhoff C, Schnare SM. Real-world patterns of prescription refills for branded hormonal contraceptives: a reflection of contraceptive discontinuation. Obstet Gynecol. 2008;112(4):782-787.

13. Gladwell M. John Rock's Error: What the co-inventor of the Pill didn't know: menstruation can endanger women's health. The New Yorker. 2000 March 13;52-63. Available from: http://www.gladwell. com/archive.html. Accessed Dec 14, 2009.

14. Marks LV. Sexual Chemistry: A History of the Contraceptive Pill. New Haven: Yale University Press; 2001.

15. Vessey M, Mant D, Smith A, Yeates D. Oral contraceptives and venous thromboembolism: findings in a large prospective study. $\mathrm{Br}$ Med J. 1986;292(6519):526.

16. Scharnagl H, Petersen G, Nauck M, Teichmann AT, Wieland H, März W. Double-blind, randomized study comparing the effects of two monophasic oral contraceptives containing ethinylestradiol (20 microg or 30 microg) and levonorgestrel (100 microg or 150 microg) on lipoprotein metabolism. Contraception. 2004;69(2):105-113.

17. Jick H, Jick SS, Gurewich V, Myers MW, Vasilakis C. Risk of idiopathic cardiovascular death and nonfatal venous thromboembolism in women using oral contraceptives with differing progestagen components. Lancet. 1995;346(8990):1589-1593.

18. Effect of different progestagens in low oestrogen oral contraceptives on venous thromboembolic disease. World Health Organization Collaborative Study of Cardiovascular Disease and Steroid Hormone Contraception. Lancet. 1995;346(8990):1582-1588.

19. Spitzer WO, Lewis MA, Heinemann LA, Thorogood M, MacRae KD. Third generation oral contraceptives and risk of venous thromboembolic disorders: an international case-control study. Transnational Research Group on Oral Contraceptives and the Health of Young Women. BMJ. 1996;312(7023):83-88.

20. Farmer RD, Lawrenson RA, Thompson CR, Kennedy JG, Hambleton IR. Population-based study of risk of venous thromboembolism associated with various oral contraceptives. Lancet. 1997;349(9045):83-88.

21. Seeger JD, Loughlin J, Eng PM, Clifford CR, Cutone J, Walker AM. Risk of thromboembolism in women taking ethinylestradiol/drospirenone and other oral contraceptives. Obstet Gynecol. 2007;110(3):587-593.

22. Dinger JC, Heinemann LA, Kühl-Habich D. The safety of a drospirenonecontaining oral contraceptive: final results from the European Active Surveillance Study on oral contraceptives based on 142,475 womenyears of observation. Contraception. 2007;75(5):344-354.

23. Lidegaard Ø, Løkkegaard E, Svendsen AL, Agger C. Hormonal contraception and risk of venous thromboembolism: national follow-up study. BMJ. 2009;339:b2890. 
24. van Hylckama Vlieg A, Helmerhorst FM, Vandenbroucke JP, Doggen CJ, Rosendaal FR. The venous thrombotic risk of oral contraceptives, effects of oestrogen dose and progestogen type: results of the MEGA case-control study. BMJ. 2009;339:b2921.

25. Kistner RW. Current status of the hormonal treatment of endometriosis. Clin Obstet Gynecol. 1966;9(2):271-292.

26. Vercellini P, Frontino G, De Giorgi O, Pietropaolo G, Pasin R, Crosignani PG. Continuous use of an oral contraceptive for endometriosisassociated recurrent dysmenorrhea that does not respond to a cyclic pill regimen. Fertil Steril. 2003;80(3):560-563.

27. Boyle CA. Management of menstrual migraine. Neurology. 1999; 53(4 Suppl 1):S14-S18.

28. Sulak P, Willis S, Kuehl T, Coffee A, Clark J. Headaches and oral contraceptives: impact of eliminating the standard 7-day placebo interval. Headache. 2007;47(1):27-37.

29. Sulak PJ, Scow RD, Preece C, Riggs MW, Kuehl TJ. Hormone withdrawal symptoms in oral contraceptive users. Obstet Gynecol. 2000;95(2):261-266.

30. Sulak PJ, Cressman BE, Waldrop E, Holleman S, Kuehl TJ. Extending the duration of active oral contraceptive pills to manage hormone withdrawal symptoms. Obstet Gynecol. 1997;89(2):179-183.

31. Willis SA, Kuehl TJ, Spiekerman AM, Sulak PJ. Greater inhibition of the pituitary - ovarian axis in oral contraceptive regimens with a shortened hormone-free interval. Contraception. 2006;74(2):100-103.

32. Schlaff WD, Lynch AM, Hughes HD, Cedars MI, Smith DL. Manipulation of the pill-free interval in oral contraceptive pill users: the effect on follicular suppression. Am J Obstet Gynecol. 2004;190(4):943-951.

33. Klipping C, Duijkers I, Trummer D, Marr J. Suppression of ovarian activity with a drospirenone-containing oral contraceptive in a $24 / 4$ regimen. Contraception. 2008;78(1):16-25. Erratum in: Contraception. 2008;78(4):350.

34. Rible RD, Taylor D, Wilson ML, Stanczyk FZ, Mishell DR Jr. Follicular development in a 7-day versus 4-day hormone-free interval with an oral contraceptive containing $20 \mathrm{mcg}$ ethinyl estradiol and $1 \mathrm{mg}$ norethindrone acetate. Contraception. 2009;79(3):182-188.

35. Miller L, Notter KM. Menstrual reduction with extended use of combination oral contraceptive pills: randomized controlled trial. Obstet Gynecol. 2001;98(5 Pt 1):771-778.

36. Coffee AL, Sulak PJ, Kuehl TJ. Long-term assessment of symptomatology and satisfaction of an extended oral contraceptive regimen. Contraception. 2007;75(6):444-449.

37. Kjerulff KH, Erickson BA, Langenberg PW. Chronic gynecological conditions reported by US women: findings from the National Health Interview Survey, 1984 to 1992. Am J Public Health. 1996;86(2):195-199.

38. Davis AR, Westhoff CL. Primary dysmenorrhea in adolescent girls and treatment with oral contraceptives. $J$ Pediatr Adolesc Gynecol. 2001;14(1):3-8.

39. Association of Reproductive Health Professionals. Extended Regimen Oral Contraceptives. Harris Poll. 2002 June 14-17.

40. Anderson FD, Hait H. A multicenter, randomized study of an extended cycle oral contraceptive. Contraception. 2003;68(2):89-96. Erratum in: Contraception. 2004;69(2):175.

41. Edelman A, Gallo MF, Nichols MD, Jensen JT, Schulz KF, Grimes DA. Continuous versus cyclic use of combined oral contraceptives for contraception: systematic Cochrane review of randomized controlled trials. Hum Reprod. 2006;21(3):573-578.
42. Kaunitz AM, Portman DJ, Hait H, Reape KZ. Adding low-dose estrogen to the hormone-free interval: impact on bleeding patterns in users of a 91-day extended regimen oral contraceptive. Contraception. 2009;79(5):350-355.

43. Anderson FD, Gibbons W, Portman D. Safety and efficacy of an extended-regimen oral contraceptive utilizing continuous low-dose ethinyl estradiol. Contraception. 2006;73(3):229-234.

44. Kwiecien M, Edelman A, Nichols MD, Jensen JT. Bleeding patterns and patient acceptability of standard or continuous dosing regimens of a low-dose oral contraceptive: a randomized trial. Contraception. 2003;67(1):9-13.

45. Miller L, Hughes JP. Continuous combination oral contraceptive pills to eliminate withdrawal bleeding: a randomized trial. Obstet Gynecol. 2003;101(4):653-661.

46. Edelman AB, Koontz SL, Nichols MD, Jensen JT. Continuous oral contraceptives: are bleeding patterns dependent on the hormones given? Obstet Gynecol. 2006;107(3):657-665.

47. Archer DF, Jensen JT, Johnson JV, Borisute H, Grubb GS, Constantine GD. Evaluation of a continuous regimen of levonorgestrel/ethinyl estradiol: phase 3 study results. Contraception. 2006;74(6):439-445.

48. Teichmann A, Apter D, Emerich J, et al. Continuous, daily levonorgestrel/ethinyl estradiol vs 21-day, cyclic levonorgestrel/ethinyl estradiol: efficacy, safety and bleeding in a randomized, open-label trial. Contraception. 2009;80(6):504-511.

49. Archer DF, Kovalevsky G, Ballagh SA, Grubb GS. Ovarian activity and safety of a novel levonorgestrel/ethinyl estradiol continuous oral contraceptive regimen. Contraception. 2009;80(3):245-253.

50. Barnhart K, Mirkin S, Grubb G, Constantine G. Return to fertility after cessation of a continuous oral contraceptive. Fertil Steril. 2009;91(5):1654-1656.

51. Davis AR, Kroll R, Soltes B, Zhang N, Grubb GS, Constantine GD. Occurrence of menses or pregnancy after cessation of a continuous oral contraceptive. Fertil Steril. 2008;89(5):1059-1063.

52. Johnson JV, Grubb GS, Constantine GD. Endometrial histology following 1 year of a continuous daily regimen of levonorgestrel 90 micro g/ethinyl estradiol 20 micro g. Contraception. 2007; 75(1):23-26.

53. Teichmann A, Apter D, Emerich J, et al. Continuous, daily levonorgestrel/ethinyl estradiol vs 21-day, cyclic levonorgestrel/ethinyl estradiol: efficacy, safety and bleeding in a randomized, open-label trial. Contraception. 2009;80(6):504-511.

54. Wagstaff AJ. Continuous-use ethinylestradiol/levonorgestrel 20microg/ 90microg: as an oral contraceptive. Drugs. 2007;67(16):2473-2477; discussion 2478-2479.

55. Andrist LC, Arias RD, Nucatola D, et al. Women's and providers' attitudes toward menstrual suppression with extended use of oral contraceptives. Contraception. 2004;70(5):359-363.

56. Kroll R, Reape KZ, Margolis M. The efficacy and safety of a low-dose, 91-day, extended-regimen oral contraceptive with continuous ethinyl estradiol. Contraception. 2010;81(1):41-48.

57. Holt VL, Scholes D, Wicklund KG, Cushing-Haugen KL, Daling JR. Body mass index, weight, and oral contraceptive failure risk. Obstet Gynecol. 2005;105(1):46-52.

58. Holt VL, Cushing-Haugen KL, Daling JR. Body weight and risk of oral contraceptive failure. Obstet Gynecol. 2002;99(5 Pt 1):820-827.

International Journal of Women's Health

\section{Publish your work in this journal}

The International Journal of Women's Health is an international, peerreviewed open-access journal publishing original research, reports, reviews and commentaries on all aspects of women's healthcare including gynecology, obstetrics, and breast cancer. Subject areas include: Chronic conditions (migraine headaches, arthritis, osteoporosis);

Endocrine and autoimmune syndromes; Sexual and reproductive health; Psychological and psychosocial conditions. The manuscript management system is completely online and includes a very quick and fair peer-review system. Visit http://www.dovepress.com/ testimonials.php to read real quotes from published authors. 